\title{
Suplementação de Novilhos Nelore em Pastejo de Brachiaria brizantha com Diferentes Níveis e Fontes de Concentrado 1
}

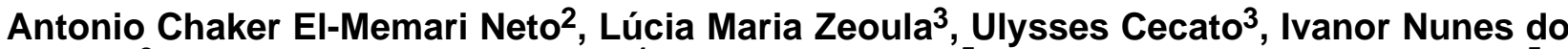 Prado $^{3}$, Saul Ferreira Caldas Neto ${ }^{4}$, Ricardo Kazama ${ }^{5}$, Fabio Cortez Leite de Oliveira ${ }^{5}$}

\begin{abstract}
RESUMO - O objetivo deste trabalho foi avaliar o ganho médio diário (GMD) de novilhos em pastejo de B.brizantha cv. Marandu, suplementados com três tipos de suplementos, no período de julho a dezembro, em dois níveis de fornecimento. Foram utilizados 54 novilhos Nelore (nove por tratamento) com idade aproximada de 20 meses e peso vivo inicial de $370 \mathrm{~kg}$. Os suplementos utilizados foram: suplemento rico em amido (AMI), rico em óleo (OLE) e suplemento composto de amido+óleo (A+O). Os suplementos foram fornecidos em níveis de 0,7 e 1,4\% do peso vivo. A disponibilidade de lâminas verdes do capim-braquiária foi de 5,12 kg de MS/100 kg de PV. Os suplementos e níveis influenciaram o ganho médio diário (GMD). Nos dois níveis de fornecimento, o suplemento A+O promoveu o melhor desempenho. No menor nível de fornecimento (0,7\% PV), os suplementos com AMI e OLE não diferiram entre si, mas ambos diferiram do suplemento A+O. Para este nível de fornecimento, o GMD foi 0,46; 0,44 e 0,57 kg para os tratamentos AMI, OLE e A+O, respectivamente. Resultados semelhantes foram observados no nível de fornecimento de 1,4\% do PV. Neste caso, o suplemento A+O foi superior ao AMI e OLE, que não diferiram entre si. O GMD foi 0,58 kg para AMI, 0,61 kg para OLE e 0,72 kg para A+O. A suplementação com concentrados compostos pela mistura de alimentos ricos em amido (milho) e óleo (caroço de algodão) proporcionou melhor desempenho dos animais em comparação aos suplementados separadamente com as respectivas fontes, independentemente do nível de suplementação. O maior nível de suplementação (1,4\% do PV) apresentou eficiência econômica inferior, quando comparada à do menor nível ( $0,7 \%$ do PV).
\end{abstract}

Palavras-chave: Brachiaria brizatha, novilhos nelore, suplementação a pasto, terminação de bovinos

\section{Supplementation of Nellore Grazing Steers with Different Sources and Concentrate Levels}

\begin{abstract}
This work was carried out to study the daily average gain (DAG) of steers grazing Brachiaria brizantha cv. Marandu, supplemented, from July to December, with two levels of three different supplements. Fifty-four Nellore steers (9 for each treatment) aged approximately 20 months and initial average live weight of $370 \mathrm{~kg}$ were used. The experimental treatments were: AMI supplement rich in starch (based on corn), OLE - supplement rich in fat (based on whole cottonseed) and A+O - supplement combination (based on mixture of AMI and OLE). All supplements were offered in .7 and 1.4\% of liveweight (LW). The green blade availability was $5.12 \mathrm{~kg} \mathrm{DM} / 100 \mathrm{~kg} \mathrm{LW}$. Treatments and levels influenced DAG. In both levels of supplementation, the combination of feeds promoted higher performance. The lowest level (.7\% LW) AMI and OLE was not different, and both were different from A+O. DAG was .44, .46, and $.57 \mathrm{~kg}$ for AMI, OLE and A+O respectively. Similar results were registered on the higher level (1.4\% LW) of supplementation. In this level A+O showed better performance than AMI and OLE that was not different. DAG was .58 $\mathrm{kg}$ for AMI, $.61 \mathrm{~kg}$ for OLE and $.72 \mathrm{~kg}$ for $\mathrm{A}+\mathrm{O}$. The supplementation with concentrates composed by the mixture of rich feeds in starch (corn) and oil (cotton seed) provided higher performance of the animals, that when supplemented separately with the respective sources, independently of the supplementation level. The higher supplementation level (1.4\% of LW) showed lower economical efficiency, when compared to the smallest level (.7\% PV).
\end{abstract}

Key Words: beef cattle finishing, Brachiaria brizantha, grazing steers supplementation, Nellore steers

\section{Introdução}

A terminação de bovinos é caracterizada pela elevação da deposição da gordura corporal e, conseqüentemente, pelo aumento na exigência energética (NRC, 1996). Dessa forma, um aporte basicamente protéico não oferece condições necessárias para obtenção de elevado desempenho produtivo, em animais, neste estado fisiológico. Assim, é destacada a necessidade de inclusão de fontes energéticas da dieta de animais em terminação. Estas fontes suplementares baseiam-se principalmente em grãos de cereais e oleaginosas, os quais apresentam elevada quantidade de carboidratos não estruturais e triglicerídeos, respectivamente.

\footnotetext{
${ }^{1}$ Parte da tese de Mestrado em Zootecnia apresentada à Universidade Estadual de Maringá.

2 Mestre em Zootecnia/UEM. E.mail: antonio@terratreinamentos.com.br

3 Professor do curso de Zootecnia PPZ/UEM. Bolsista do CNPq. Av. Colombo, 5790, Maringá, PR, CEP: 87020-900. E.mail: Imzeoula@uem.br

4 Doutorando em Zootecnia PPZ/UEM, Maringá, PR.

5 Graduando do curso de Zootecnia da UEM. E.mail: ricardokazama@hotmail.com
} 
As variações entre as fontes energéticas relacionam-se com o substrato, tipo e local de digestão. Diversas fontes energéticas são fermentadas no rúmen com a produção de diferentes ácidos graxos voláteis. Por outro lado, existem ainda fontes energéticas que escapam da fermentação ruminal e sofrem processo de digestão química semelhante ao ocorrido com animais não ruminantes. Diante destes fatos, observaram-se diferentes vias metabólicas com o mesmo objetivo final, que é o suprimento energético líquido.

Entre os carboidratos não estruturais, o amido caracteriza-se como a principal fonte de suplementação. A degradação ruminal do amidoé, na sua maior porção, executada pelas bactérias amilolíticas, sendo em menor escala hidrolisado por fungos e protozoários (Huntington, 1997).

Além do amido, os lipídeos são fornecidos como fontes suplementares, já que são componentes principais de oleaginosas de ampla utilização na dieta de ruminantes. As fontes de lipídeos que tem se destacado na alimentação de ruminantes são, principalmente, semente de soja, algodão e canola.

Segundo Van Soest (1994), a utilização de ácidos graxos pelas bactérias ruminais é restrita. $\mathrm{O}$ excesso de ácidos graxos insaturados e triglicerídeos pode causar alteração na fermentação ruminal, devida à supressão das atividades de bactérias celulolíticas e metanogênicas, geralmente, gram positivas. O mesmo efeito não é observado quando se utilizam fontes saturadas. Informações semelhantes são descritas por Villela et al. (1997) e Zinn \& Pascencia (1997).

O objetivo deste trabalho foi avaliar o efeito dos diferentes níveis $(0,7$ e $1,4 \%$ PV) e fontes de suprimento energético (amido e óleo), bem como sua mistura sobre desempenho de novilhos nelore em pastejo de capim B.brizantha (hoecht) Staf cv. Marandu, em fase de terminação.

\section{Material e Métodos}

\section{Identificação do local}

O experimento a campo foi realizado no período de transição secas-águas, compreendendo os meses de julho a dezembro de 2001.

Estabeleceu-se que cada período experimental compunha-se de 30 dias, quando foram executadas as avaliações de desempenho e caracterização da forragem.

Foram utilizados 54 novilhos Nelore castrados com peso médio de $370 \pm 24 \mathrm{~kg}$ e idade média de 20 meses. Todos os animais foram vermifugados, no início do experimento, com medicamento à base de abamectina (Abamectina Ouro Fino ${ }^{\circledR}$ ) e banhados contra ectoparasitas, conforme a necessidade. Os animais foram marcados através de ferro quente, recebendo também identificação por brincos de diferentes cores por tratamento. Os novilhos foram randomizados de acordo com o peso para formação dos lotes e estes alocados ao acaso nos diferentes tratamentos.

Foi utilizada uma área total de 24 ha de capim B.brizantha (hoecht) Staf cv. Marandu dividida em seis piquetes de 4,0 ha. Para minimizar a interferência das diferenças entre os piquetes, os animais foram mudados de piquete a cada cinco dias e, dessa forma, a cada período de 30 dias, todos os animais em seus respectivos lotes pastejaram os seis piquetes. A lotação média do período foi de 2,4 animais/ha ou 2,1 UA/ha, sendo a oferta média de lâminas verdes de $5,12 \mathrm{~kg} / 100 \mathrm{~kg}$ de peso vivo.

A técnica utilizada para manter disponibilidade adequada e equilibrada de pastagem foi o método de Put and Take, descrito por Mott e Lucas (1952).

A determinação da disponibilidade da forragem ou resíduo de matéria seca (RMS) foi realizada a cada 30 dias, utilizando o método de dupla amostragem (Wilm et al., 1944).

Os alimentos que compuseram os suplementos concentrados foram milho, caroço de algodão, farelo de algodão, casca de soja e farelo de trigo, cuja composição química se encontra na Tabela 1. Os suplementos concentrados se caracterizam em rico em amido (AMI), rico em óleo (OLE) e composto por amido + óleo $(\mathrm{A}+\mathrm{O})$. Foram fornecidos em dois níveis de consumo: 0,7 e 1,4\% do PV, totalizando seis tratamentos (três tipos de suplementos e dois níveis de fornecimento).O fornecimento do suplemento foi corrigido a cada 30 dias, quando da pesagem dos animais.

As composições percentuais e químicas dos suplementos concentrados são apresentadas na Tabela 2 .

Para animais que receberam suplementação de $1,4 \%$ do peso vivo, o fornecimento diário foi dividido em duas refeições: às 8 e 16h. Quando a suplementação foi de $0,7 \%$ do PV, os animais receberam apenas uma vez ao dia, às $8 \mathrm{~h}$. A área de cocho destinada aos animais foi de $60 \mathrm{~cm} /$ animal.

Os animais foram pesados no início do experimento e a cada 30 dias, totalizando cinco períodos.

Os teores de matéria seca (MS), proteína bruta (PB), fibra bruta (FB), extrato etéreo (EE), extrativo 
não nitrogenado (ENN), fibra detergente neutro(FDN) e fibra detergente ácido (FDA) dos suplementos foram determinados segundo a metodologia de Weende e pelo método de partição de fibras (método de Van Soest), conforme Silva (1990). Os teores de amido foram avaliados pelo método enzimático preconizado por Poore et al. (1989), modificado para leitura por Pedreira \& Rossi (1995). Para as forragens, os teores de PB foram determinados, conforme Silva (1990), e a DIVMS foi realizada de acordo com a metodologia de Tilley \& Terry (1963) adaptada para utilização do rúmen artificial, desenvolvida por $\mathrm{ANKON}^{\circledR}$, conforme descrito por Holden (1999).

A degradabilidade foi estimada pela técnica in situ do saco de náilon. As amostras de concentrado foram incubadas em cada um dos animais, em delineamento de blocos casualizados. Os tempos de incubação foram de $0,2,4,6,8,12,16,24,48$, e 72 horas. O delineamento experimental utilizado foi de blocos casualizados. Utilizou-se a equação descrita por Mehrez \& Orskov (1977).

As variáveis foram analisadas por meio de análise de variância utilizando o Sistema de Análises Estatísticas e Genéticas - SAEG (UFV, 1997) e comparadas pelo teste de Tukey a 1 e $5 \%$ de probabilidade, de acordo com o seguinte modelo:

Tabela 1 - Composição química (\%/MS) dos ingredientes utilizados nos suplementos

Table 1 - Chemical composition (\%/DM) of ingredients used in the supplements

\begin{tabular}{lrrrrr}
\hline & \multicolumn{5}{c}{ Ingredientes (Ingredients) } \\
\cline { 2 - 7 } & FA & CS & \multicolumn{1}{c}{ FT } & CA & MI \\
& \multicolumn{1}{c}{ CM } & \multicolumn{1}{c}{$S H$} & \multicolumn{1}{c}{$W M$} & \multicolumn{1}{c}{$W C$} & \multicolumn{1}{c}{$C O$} \\
\hline MS $(D M) \%$ & 85,68 & 84,88 & 83,06 & 86,45 \\
PB (CP) \% & 40,58 & 11,48 & 22,05 & 22,15 & 10,55 \\
FB (CF) \% & 23,79 & 32,40 & 8,71 & 31,30 & 3,61 \\
FDN (NDF) \% & 42,80 & 47,48 & 32,86 & 43,32 & 23,91 \\
FDA (ADF) \% & 29,74 & 40,50 & 10,88 & 39,13 & 4,52 \\
Amido (Starch) \% & - & - & 32,08 & - & 71,53 \\
EE (EE) \% & 4,18 & 1,20 & 7,48 & 17,58 & 2,81 \\
ENN (NNE) \% & 25,59 & 44,22 & 56,68 & 24,61 & 77,12 \\
MM (MM) \% & 5,85 & 3,70 & 5,08 & 4,36 & 1,77 \\
NDT (TDN) \% & 60,77 & 72,71 & 76,27 & 71,64 & 78,61 \\
EM (ME) Mcal/kg & 2,20 & 2,63 & 2,76 & 2,59 & 2,84 \\
\hline FA: & &
\end{tabular}

FA: farelo de algodão, CS: casca de soja, FT: farelo de trigo, CA: caroço de algodão, MI: milho.

CM: cotonseed meal, SH: soybean hulls, WM: wheat meal, WC: whole cottonseed, CO: corn.

R. Bras. Zootec., v.32, n.6, p.1945-1955, 2003 (Supl. 2)

$$
\mathrm{Y}_{i j k l}=u+\mathrm{T}_{i}+\mathrm{N}_{\mathrm{j}}+\mathrm{P}_{k}+\mathrm{T}_{i} \mathrm{~N}_{j}+\mathrm{T}_{i} \mathrm{P}_{k}+\mathrm{N}_{j} \mathrm{P}_{k}+\mathrm{e}_{i j k l}
$$

em que $\mathrm{Y}_{i j k l}=$ valor observado da variável estudada do indivíduo 1 no período $\mathrm{k}$, recebendo o nível $\mathrm{j}$ do tratamento $i ; u=$ constante geral; $\mathrm{T}_{i}=$ efeito do

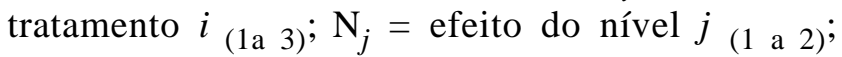

Tabela 2 - Composição percentual e química dos suplementos concentrados

Table 2 - Percentual and chemical composition of the concentrated supplements

\begin{tabular}{|c|c|c|c|}
\hline & \multicolumn{3}{|c|}{$\begin{array}{c}\text { Composição do } \\
\text { suplemento (\%) } \\
\text { Supplement composition }\end{array}$} \\
\hline & AMI & OLE & $\mathrm{A}+\mathrm{O}$ \\
\hline $\begin{array}{l}\text { Caroço de algodão } \\
\text { Whole cottonseed }\end{array}$ & 0 & 39,00 & 20,00 \\
\hline $\begin{array}{l}\text { Casca de soja } \\
\text { Soybean hulls }\end{array}$ & 0 & 41,50 & 17,5 \\
\hline $\begin{array}{l}\text { Farelo de trigo } \\
\text { Wheat meal }\end{array}$ & 2,5 & 10,50 & 8,8 \\
\hline $\begin{array}{l}\text { Farelo de algodão } \\
\text { Cottonseed meal }\end{array}$ & 17,4 & 8,50 & 13,50 \\
\hline $\begin{array}{l}\text { Milho } \\
\text { Corn }\end{array}$ & 78,0 & 0,00 & 39,00 \\
\hline $\begin{array}{l}\text { Uréia + Enxofre }(12 \mathrm{~N}: 1 \mathrm{~S}) \\
\text { Urea+ Sulfur(12N:1S) }\end{array}$ & 2,1 & 0,50 & 1,20 \\
\hline $\begin{array}{l}\operatorname{MS}(\%) \\
D M\end{array}$ & 86,45 & 84,59 & 85,47 \\
\hline $\begin{array}{l}\mathrm{PB}(\%) \\
\mathrm{CP}\end{array}$ & 21,85 & 20,60 & 21,40 \\
\hline $\begin{array}{l}\mathrm{FB}(\%) \\
\mathrm{CF}\end{array}$ & 7,18 & 28,59 & 17,32 \\
\hline $\begin{array}{l}\mathrm{FDN}(\%) \\
N D F\end{array}$ & 26,92 & 43,69 & 34,97 \\
\hline $\begin{array}{l}\text { FDA }(\%) \\
A D F\end{array}$ & 8,97 & 35,74 & 21,65 \\
\hline $\begin{array}{l}\text { Amido }(\%) \\
\text { Starch }\end{array}$ & 56,59 & 3,37 & 30,72 \\
\hline $\begin{array}{l}\mathrm{EE}(\%) \\
\mathrm{ENN}(\%)\end{array}$ & $\begin{array}{r}3,11 \\
66,02\end{array}$ & $\begin{array}{r}8,50 \\
36,08\end{array}$ & $\begin{array}{r}6,05 \\
51,18\end{array}$ \\
\hline$N N E$ & & & \\
\hline $\begin{array}{l}\mathrm{MM}(\%) \\
M M\end{array}$ & 2,53 & 4,27 & 3,45 \\
\hline $\begin{array}{l}\operatorname{NDT}(\%) \\
T D N\end{array}$ & 73,79 & 71,29 & 72,63 \\
\hline $\begin{array}{l}\mathrm{EM} \mathrm{Mcal} / \mathrm{kg} \\
M E\end{array}$ & 2,67 & 2,58 & 2,63 \\
\hline
\end{tabular}

AMI: suplemento rico em amido, OLE: suplemento rico em óleo, A+O: suplemento de amido+óleo.

AMI: supplement rich in starch, OLE: supplement rich in oil, $A+O$ : supplement of starch +oil. 
$\mathrm{P}_{k}=$ efeito do período $k_{(1 \mathrm{a} 4)} ; \mathrm{T}_{i} \mathrm{~N}_{j=}$ efeito da interação o tratamento $i$ e o nível $j ; \mathrm{T}_{i} \mathrm{P}_{j=}$ efeito da interação o tratamento $i$ e o período $k ; \mathrm{N}_{j} \mathrm{P}_{k}=$ efeito da interação o nível $\mathrm{j}$ e o período $\mathrm{k} ; \mathrm{e}_{i j k l}=$ erro aleatório associado a cada observação.

Foram avaliados, por meio do desempenho animal nos diferentes tratamentos, os parâmetros de reposta econômica seguindo a metodologia utilizada por Euclides et al. (1997).O valor de comercialização da @ praticado na venda dos animais do experimento variou entre $R \$ 40,00$ a $R \$ 43,00$. Oinvestimento diário para cada tratamento é apresentado na Tabela 3.

Foram calculados para todos os tratamentos e níveis os valores presentes líquido (VPL), taxa interna de retorno (TIR) a razão benefício custo $(\mathrm{B} / \mathrm{C})$, conforme descrito por Dossa et al. (1991) e Magalhães (1995).

\section{Resultados e Discussão}

Foram registradas diferenças entre os suplementos fornecidos $(\mathrm{P}<0,05)$, níveis de suplementação e períodos $(\mathrm{P}<0,01)$. Não foi observada diferença para as interações.

Os dados de peso vivo inicial, consumo diário do suplemento e desempenho animal são apresentados na Tabela 4.

Para o menor nível de suplementação, $0,7 \%$ do peso vivo $(0,7 \% \mathrm{PV})$, os animais que receberam o suplemento amido + óleo $(\mathrm{A}+\mathrm{O})$ apresentaram ganho de peso vivo médio diário (GMD) de 572,5g, sendo assim superior em relação àqueles que receberam os suplementos à base de amido (AMI) de 457,3 g ou de óleo (OLE) de 437,5 g, os quais não deferiram entre si. O mesmo comportamento foi observado para o nível de suplementação de 1,4\% PV. O ganho médio diário dos animais que receberam a suplementação com $\mathrm{A}+\mathrm{O}$ foi de 716,5 g/anim./dia que diferiu daqueles que receberam o suplemento com AMI $(575,9 \mathrm{~g})$ ou com OLE $(611,2 \mathrm{~g})$, os quais não diferiram entre si. Nota-se que, em ambos os níveis de suplementação ( 0,7 e 1,4\% PV), a mistura de alimentos milho + caroço de algodão $(\mathrm{A}+\mathrm{O})$, ou melhora mistura dos nutrientes amido +óleoproporcionou maior desempenho dos animais.

Evidenciou-se, diante desta característica, o efeito associativo positivo entre os alimentos. Segundo Huck et al. (1998), este efeito se caracteriza quando o desempenho animal é superior aquele predito baseado nas médias dos grãos fornecidos separadamente. Os possíveis mecanismos para ação do efeito associativo referem-se à melhor dinâmica de degradação ruminal, bem como de absorção intestinal, quando ocorre a utilização da mistura de alimentos.

Observa-se que os ganhos médios registrados no experimento são menores que os apresentados na literatura para período, nível de suplementação e características de suplementos semelhantes. Ressalta-se que o GMD para todo período experimental foi de 489,1 e 634,5 g para 0,7 e $1,4 \%$ do $P V$, respectivamente para os suplementos que continham em média $21 \%$ de PB e $72 \%$ de NDT.

A variação de desempenho quando adotada a suplementação em pastejo na época seca é elevada. Como destacado por Alberto (1997), o desempenho com suplementação em pastejo é determinado pela interação de uma gama de fatores. Desta forma, diferenças registradas entre os trabalhos podem estar ligados aos parâmetros relacionados às interações forragem:suplemento:animal, as quais são caracterizadas individualmente a cada experimento.

Apesar da literatura apontar maiores ganhos que os obtidos no presente trabalho, Thiago (1999) descreveu que um suplemento de, aproximadamente, $20 \%$ de PB e $80 \%$ de NDT e nível de suplementação de 0,8 a $1 \%$ do PV e boa disponibilidade de forragem permite um ganho aproximado de $500 \mathrm{~g}$. Esta informação admite o ganho médio diário (GMD) obtido no experimento dentro da faixa esperada. Por outro lado, o pequeno diferencial de $145 \mathrm{~g}$ registrado entre as médias de GMD obtidas para os níveis de fornecimento de 0,7 e $1,4 \%$ do PV são relativamente baixos, apontando possíveis efeitos negativos relacionados ao elevado nível de suplementação.

Os impactos negativos da sobrecarga ruminal do amido, quando fornecido em maiores quantidades na ração, referem-se principalmente a reduções de $\mathrm{pH}$ e conseqüente digestibilidade da forragem, já que as bactérias celulolíticas são sensíveis à queda de $\mathrm{pH}$ (Caton \& Dhuyvetter, 1997). A elevação de carboidratos não estruturais da dieta fornece maior aporte de substrato para os microorganismos produtores de propionato. Ocorre maior produção total de ácidos graxos voláteis (AGV), bem como a maior produção individual de lactato e conseqüente queda no pH ruminal (Russel, 1998). Este acúmulo de ácidos no rúmen pode causar danos ao epitélio do rúmen e inibir a atividade dos microrganismos celulolíticos (Orskov et al., 1971, citados por Zeoula \& Caldas Neto, 2001) e induzir reduções na ingestão da forragem e na ingestão total de matéria seca (Grant, 1994) pela redução na digestibilidade da fibra.

Além do aspecto da redução do $\mathrm{pH}$, outro fator 
que pode ter influenciado nos resultados é a elevação do fluxo intestinal do amido, quando grandes quantidades são fornecidas (Zeoula \& Caldas Neto, 2001). Segundo revisão realizada por estes autores, o aumento no fluxo intestinal de amido é inversamente relacionado com sua digestão.

Owens et al. (1986) enumeraram os seguintes fatores como os possíveis responsáveis pelas limitações da digestão do amido no intestino delgado: 1) limitação da amilase, maltase ou isomaltase, devido à inadequada produção, presença de enzimas inibidoras ou as variações do $\mathrm{pH}$ intestinal; 2) limitada capacidade de absorção de glicose pelo intestino delgado; 3) tempo insuficiente para a completa hidrólise e 4) inadequado acesso das enzimas ao grânulo de amido.

Segundo Harmon (1993), a concentração de $\alpha$-amilase pancreática é aumentada com a elevação do nível energético da dieta, mas não com a elevação na ingestão de carboidratos. Huntington (1997) descreve que o aumento do fluxo de proteína para o

Tabela 3 - Descrição dos valores componentes do custo da suplementação Table 3 - Description of the values of supplementation costs

\begin{tabular}{lccc}
\hline $\begin{array}{l}\text { Nível de suplementação } \\
\text { Level of supplementation }\end{array}$ & AMI & OLE & $\mathrm{A}+\mathrm{O}$ \\
\hline $\begin{array}{l}0,7 \% \text { PV de suplementação } \\
7 \% \text { LW of supplementation }\end{array}$ & $\mathrm{R} \$ 0,675$ & $\mathrm{R} \$ 0,512$ & $\mathrm{R} \$ 0,612$ \\
$\begin{array}{l}1,4 \% \text { PV de suplementação } \\
1.4 \% \text { LW of supplementation }\end{array}$ & $\mathrm{R} \$ 1,383$ & $\mathrm{R} \$ 1,056$ & $\mathrm{R} \$ 1,250$ \\
\hline $\begin{array}{l}\text { AMI: suplemento rico em amido, OLE: suplemento rico em óleo, A+O: suplemento de } \\
\text { amido+óleo. } \\
\text { AMI: supplement rich in starch, OLE: supplement rich in oil, A+O: supplement of starch + oil. }\end{array}$
\end{tabular}

Tabela 4 - Peso vivo médio inicial (PVI), consumo médio diário do suplemento (CMS), ganho de peso vivo médio diário (GMD) dos animais submetidos aos diferentes níveis e fontes de suplementos concentrados

Table 4 - Initial body weight (IBW), supplement average daily intake (SAI) and daily average gain (DAG) of animals fed different levels and sources of concentrated supplement

\begin{tabular}{lcccr}
\hline $\begin{array}{l}\text { Suplemento } \\
\text { Supplement }\end{array}$ & $\begin{array}{r}\text { Nivel }(\% \text { do PV) } \\
\text { Level }(\% L W)\end{array}$ & $\begin{array}{c}\text { PVI }(\mathrm{kg}) \\
I B W(k g)\end{array}$ & $\begin{array}{r}\text { CMS (kg/an./dia) } \\
\text { SAI }(\mathrm{kg} / \text { an./dia })\end{array}$ & $\begin{array}{r}\text { GMD }(\mathrm{g}) \\
D A G(g)\end{array}$ \\
\hline AMI & 0,7 & 373,0 & 2,7 & $457,3 \mathrm{~B}$ \\
OLE & 0,7 & 370,0 & 2,8 & $437,5 \mathrm{~B}$ \\
A+O & 0,7 & 371,5 & 2,8 & $572,5 \mathrm{~A}$ \\
Média & 0,7 & 371,2 & 2,8 & 489,1 \\
Mean & & & & \\
AMI & 1,4 & 370,1 & 5,6 & $575,9 \mathrm{~B}$ \\
OLE & 1,4 & 374,0 & 5,8 & $611,2 \mathrm{~B}$ \\
A+O & 1,4 & 370,0 & 5,7 & $716,5 \mathrm{~A}$ \\
Média & 1,4 & 371,3 & 5,7 & 634,5 \\
Mean & & & &
\end{tabular}

AMI: suplemento rico em amido, OLE: suplemento rico em óleo, $A+O$ : suplemento de amido+óleo.

AMI: supplement rich in starch, OLE: supplement rich in oil, $A+O$ : supplement of starch +oil.

Letras diferentes na mesma coluna dentro do mesmo nível de fornecimento são diferentes pelo teste Tukey $(\mathrm{P}<0,05)$, letras diferentes nas médias são diferentes pelo teste de Tukey $(\mathrm{P}<0,01)$.

Different letter in the same columm and level of supply are different $(P<.05)$ by Tukey test, different letter in the means are different $(P<.01)$ by Tukey test. 
intestino delgado acarreta um aumento na síntese de amilase pancreática e conseqüente elevação na eficiência de utilização intestinal do amido. O maior aporte protéico no intestino pode ser resultante da utilização de fontes de proteína de baixa degradabilidade ruminal ou pela elevação na produção de proteína microbiana. Esta, por sua vez, depende da sincronização da degradabilidade ruminal entre as fontes de proteína e amido.

O limite superior relatado para a ótima digestão do amido no intestino para animais em crescimento é de 480 a 960 g/dia (Kreikemeier, 1991). Se considerar que o suplemento rico em amido (AMI) contém 57\% de amido (Tabela 2), que 30\% do amido do milho escapa da fermentação ruminal (Coelho da Silva \& Leão, 1979) e que praticamente todo amido presente no suplemento AMI foi oriundo do milho $(78 \%$ de milho na composição), pode-se inferir que o fluxo de amido para o intestino foi da ordem de 479 e $975 \mathrm{~g} / \mathrm{dia}$ para os níveis de 0,7 e 1,4\% do PV, respectivamente. Portanto, para o maior nível de suplementação, verifica-se que o fluxo de amido estaria no limite superior de $960 \mathrm{~g} /$ dia. Se a suplementação de 1,4\% do PV causou eventuais problemas metabólicos gerados pela sobrecarga ruminal do amido, pode ter afetado a síntese de proteína microbiana e, conseqüentemente, a produção de $\alpha$-amilase pancreática, limitando o aproveitamento intestinal do amido.

Não apenas o excesso de carboidratos não estruturais, mas também os lipídeos podem alterar a fermentação ruminal. Segundo Valadares Filho (2000), em geral, os efeitos da adição de lipídeos sobre a fermentação ruminal parecem depender da quantidade e da fonte dos mesmos. Os lipídeos insaturados e os ácidos graxos de cadeia curta apresentam mais efeitos do que os saturados e os ácidos graxos de cadeia longa, enquanto os sabões de cálcio apresentam mínimos efeitos sobre a fermentação ruminal. A digestão no rúmen dos carboidratos estruturais é reduzida pela adição de lipídeos às dietas e o grau de redução depende das fontes de fibra e de lipídeos, enquanto que a fermentação ruminal do amido é menos, ou não é influenciada pela adição de lipídeos (Galyean \& Owens, 1991).

O efeito negativo da utilização de gordura também é descrito por Van Soest (1994), destacando que a utilização de ácidos graxos pelas bactérias ruminais é restrita. Neste caso, o excesso de ácidos graxos insaturados e triglicerídeos pode causar a supressão das bactérias celulolíticas e metanogênicas. Maczulac et al. (1981) descreveram que este efeito é devido à ligação dos lipídeos com a membrana celular das bactérias fibrolíticas, dificultando assim a absorção de nutrientes. Além disso, é descrita a possibilidade das gorduras cobrirem as partículas dos alimentos e inibir a colonização e digestão dos carboidratos (Santos \& Almstanden, 1991).

É importante destacar que os efeitos indesejáveis descritos acima estão mais estreitamente relacionados com perdas econômicas do que sanitárias. Isto se deve ao fato de o primeiro impacto ser a diminuição do desempenho e, apenas após, a apresentação patogênica dos distúrbios metabólicos.

A sincronização na degradação de fontes de proteína e carboidratos pode levar a uma maximização da eficiência microbiana e em conseqüência elevação no desempenho (NRC, 1996). Os parâmetros de degradabilidade ruminal da matéria seca (MS) dos diferentes suplementos são apresentados na Tabela 5.

Observam-se os menores valores $(\mathrm{P}<0,01)$ de degradabilidade potencial e degradabilidade efetiva da MS, para as diferentes taxas de passagem de sólidos, para o suplemento OLE e as maiores para o suplemento AMI e intermediárias para $\mathrm{A}+\mathrm{O}$. O desempenho animal pode estar correlacionado com a característica de degradação registrada. A elevada taxa de degradação da MS pode não ser benéfica, pois gera distúrbios metabólicos, como discutido anteriormente. Este fato observado para o suplemento à base de AMI pode ser um dos responsáveis pelo baixo desempenho observado, já que nenhum tipo de controlador de fermentação foi utilizado. Por outro lado, a menor degradabilidade da MS do suplemento que continha OLE pode não ter fornecido quantidades adequadas de carboidratos e proteínas fermentáveis, sendo que este fornecimento parcial, refletiu em menores ganhos de peso. Já o suplemento $\mathrm{A}+\mathrm{O}$, o qual proporcionou melhor ganho de peso dos animais, pode ter oferecido melhores condições para uma fermentação ruminal relativamente mais equilibrada e em conseqüência ter afetado positivamente o desempenho.

Diante da característica de desempenho registrada em ambos os níveis de suplementação e nos diferentes suplementos concentrados, fica aparente que a combinação de diferentes fontes alimentares distribuiu os nutrientes, de modo que não sobrecarregou os sítios de digestão e absorção, e, conseqüentemente, promoveu maior aporte nutricional ao animal, resultando em melhor desempenho.

Outro resultado com efeito significativo $(\mathrm{P}<0,01)$ 
foi o nível de suplementação (Tabela 4). Os animais que receberam $1,4 \%$ do peso vivo apresentaram maior desempenho. $\mathrm{O}$ grande propósito, já que se espera maior desempenho em níveis tão distintos de suplementação, é avaliar o diferencial de desempenho e seu impacto no sistema de produção. Os ganhos médios diários foram 489 e $634 \mathrm{~g} / \mathrm{animal} /$ dia para os níveis 0,7 e $1,4 \%$ do peso vivo, respectivamente. A diferença entre os níveis de suplementação gerada pelo consumo de $2,91 \mathrm{~kg}$ de concentrado, a mais, foi de 145 gramas de peso vivo/dia. Ficou demonstrado que o aporte de aproximadamente 2,2 $\mathrm{kg}$ de NDT fornecidos a mais, refletiu numa superioridade de $29,65 \%$ no desempenho, para os animais suplementados com o maior nível. Em simulação, utilizando-se o NRC (1996), a diferença para bovinos consumindo este nível a mais de NDT seria de $67,27 \%$. Este fato evidencia que houve substituição, isto é, unidade trocada da forragem consumida por unidade da suplementação fornecida (Pordomingo et al., 1991) do NDT da pastagem pelo do suplemento. Provavelmente, esta substituição reduziu de forma drástica o volume energético diferencial fornecido aos animais em suplementação de 1,4\% do PV. Apesar de não ter sido efetuada mensuração direta de consumo de forragem e, conseqüentemente, de eventuais substituições, observou-se que o diferencial entre o desempenho dos animais suplementados nos

Tabela 5 - Degradabilidade potencial da matéria seca (DPMS) e degradabilidade efetiva (DE) da matéria seca (MS) dos suplementos para taxas de passagem de 2, 5 e $8 \% / h$

Table 5 - Potential dry matter degradability (PDMD) and effective degradability (ED) of supplements to passage rates of 2,5 , and $8 \% / h$

\begin{tabular}{lrrrr}
\hline Concentrados & DPMS & & \multicolumn{2}{c}{ DE (\%) } \\
Concentrates & PDMD & & ED (\%) \\
\cline { 3 - 5 } & & $2(\% / \mathrm{h})$ & $5(\% / \mathrm{h})$ & $8(\% / \mathrm{h})$ \\
\hline AMI & $94,76 \mathrm{~A}$ & $80,88 \mathrm{~A}$ & $69,17 \mathrm{~A}$ & $62,30 \mathrm{~A}$ \\
OLE & $77,63 \mathrm{C}$ & $63,45 \mathrm{C}$ & $52,99 \mathrm{C}$ & $47,36 \mathrm{C}$ \\
$\mathrm{A}+\mathrm{O}$ & $84,38 \mathrm{~B}$ & $72,03 \mathrm{~B}$ & $61,15 \mathrm{~B}$ & $54,56 \mathrm{~B}$ \\
\hline
\end{tabular}

AMI: suplemento rico em amido, OLE: suplemento rico em óleo, A+O: suplemento de amido+óleo.

AMI: supplement rich in starch, OLE: supplement rich in oil, $A+O$ : supplement of starch +oil.

Letras diferentes na mesma linha são diferentes pelo teste de Tukey $(P<0,01)$.

Different letter in the same line are different $(P<.01)$ by Tukey test. níveis de suplementação 0,7 e $1,4 \%$ do PV reduziu expressivamente com a melhoria da qualidade do capim. A elevação na qualidade nutritiva da forragem pode ser observada na elevação residual de lâminas verdes apresentada na Tabela 6 . Diante destes fatos, possivelmente, houve efeito de substituição como esperado e demonstrado por diversos autores (Moore et al., 1999; Ribeiro, 1999; Thiago, 1999).

A disponibilidade de forragem está diretamente relacionada com a produção por animal. Quanto maior for a disponibilidade maior será o ganho individual até um limite de equilíbrio. Por outro lado, em condições de subpastejo, a dieta selecionada será de baixa qualidade nutricional. Nestas condições, o alongamento do caule, o avanço do estádio fenológico das espécies e a reduzida ou ausente propriedade de rebrote das plantas fazem com que os animais tenham à sua disposição grande proporção de material forrageiro de baixa qualidade nutricional, sendo obrigados a consumi-los, por questão de sobrevivência (Maraschin, 1994). Na Tabela 6, encontram-se os níveis residuais de matéria seca para as diferentes frações da forragem.

Observou-se crescente oferta de lâminas verdes a partir do mês de agosto, a qual se estabiliza no mês de dezembro. É importante destacar que os níveis residuais apresentados para o mês de julho não apresentaram impacto sobre o desempenho animal, haja vista que logo após a amostragem as características se modificaram devida incidência de geadas. Observou-se que, na maior parte do experimento, os teores protéicos estiveram abaixo de 7,00\%, nível mínimo para a atender a demanda de nitrogênio exigido pelas bactérias ruminais. Os teores médios de PB e DIVMS durante o período experimental foram de 6,04 e 51,32\%, respectivamente, refletindo baixa qualidade média da forragem neste período.

A produção por animal é constante até atingirem um ponto crítico de oferta de forragem, e além deste ponto o ganho por animal é inversamente relacionado com a lotação. Por outro lado, o ganho por área aumenta linearmente com a lotação, até o ponto crítico e diminui linearmente com maiores aumentos da lotação (Mott \& Lucas, 1952).

Diante destes fatos, pode-se inferir que o comportamento do desempenho no decorrer dos períodos esteve diretamente relacionado com a disponibilidade de lâmina e matéria seca verde nos períodos experimentais.

Os períodos apresentaram efeito significativo 
$(\mathrm{P}<0,01)$ sobre o desempenho animal, porém, a interação período e suplemento não foi observada. $\mathrm{O}$ desempenho em função do período é apresentado na Figura 1.

Em razão de os animais suplementados no nível de $1,4 \%$ do peso vivo terem sido encaminhados ao abate no início do mês de dezembro, a aferição do desempenho destes animais neste mês não foi possível, conforme podemos observar na Figura 1.

Houve efeito quadrático $(\mathrm{y}=-0,51583+0,6045 \mathrm{x}$ $\left.0,006982 \mathrm{x}^{2}\right)$ e linear $(\mathrm{y}=0,006651+0,251515 \mathrm{x})$ para o GMD dos animais noperíodoparas os lotes suplementados com 0,7 e $1,4 \%$ do peso vivo, respectivamente.

A evolução da pecuária de corte está estreitamente relacionada com a redução de idade ao abate. Tecnologias nutricionais, bem como melhoramento genético, estão em constante busca da redução da idade ao abate. Além da melhora na qualidade da carne, a redução da idade ao abate, muitas vezes, traduz redução de custos e conseqüente elevação no resultado econômico da exploração. Adiantamento de capital e liberação de áreas de pastagem são vantagens diretas, quando se reduz a idade ao abate. Normalmente, as estratégias nutricionais são aplicadas no inverno, promovendo o abate dos animais ainda no período de entressafra. Apesar de não ser significativa como em anos anteriores e, possivelmente, não existir, no futuro, o diferencial do valor da @ do animal comercializado neste período ainda pode ser observado. Os dados referentes ao dias de suplementação para o abate são apresentados na Tabela 7.

Elevadas diferenças quanto aos dias de suplementação necessárias para o abate dos animais (DPA) foram registradas. Observou-se maior diferencial, correspondendo a 79 dias para o abate entre os animais suplementados com AMI em nível de 0,7\% do PV (205 dias) e A+O em nível de 1,4\% do PV (126 dias). Para ambos níveis de suplementação, as maiores diferenças foram entre os animais

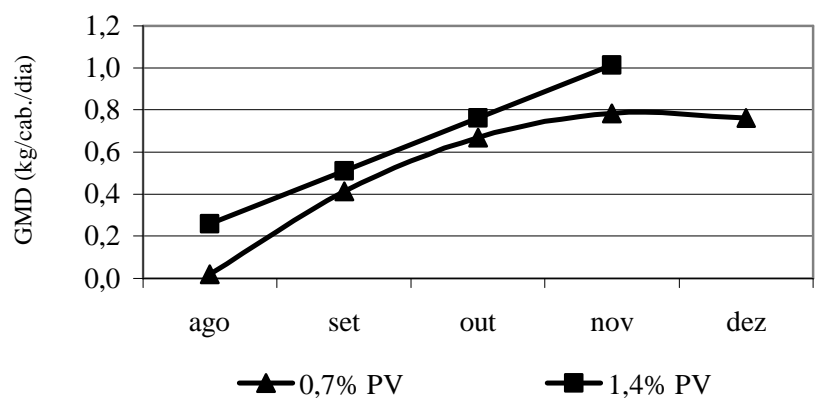

Figura 1 - Efeito do período no desempenho dos bovinos suplementados nos níveis 0,7 e $1,4 \%$ do PV.

Figure 1 - Period effect on performance of beef cattle supplemented with .7 and $1.4 \%$ LW.

Tabela 6 - Nível do resíduo por hectare da matéria seca de lâminas (RL), matéria seca verde (RMSV), matéria seca total (RT), proteína bruta (PB) e coeficiente de digestibilidade in vitro da MS (DIVMS) da B. brizantha, durante o período experimental

Table 6 - Residual level of blades (LR), green dry matter (GDMR), total dry matter residue (TR), crude protein (CP) and in vitro digestibility (IVDMD) of $B$. brizantha, during the experimental period

\begin{tabular}{|c|c|c|c|c|c|c|c|}
\hline & \multicolumn{7}{|c|}{$\begin{array}{c}\text { Período experimental } \\
\text { Experimental period }\end{array}$} \\
\hline & $\begin{array}{l}\text { Julho } \\
\text { July }\end{array}$ & $\begin{array}{l}\text { Agosto } \\
\text { August }\end{array}$ & $\begin{array}{l}\text { Setembro } \\
\text { September }\end{array}$ & $\begin{array}{r}\text { Outubro } \\
\text { October }\end{array}$ & $\begin{array}{l}\text { Novembro } \\
\text { November }\end{array}$ & $\begin{array}{l}\text { Dezembro } \\
\text { December }\end{array}$ & $\begin{array}{l}\text { Média } \\
\text { Mean }\end{array}$ \\
\hline $\begin{array}{l}\mathrm{RL}(\mathrm{kg} / \mathrm{ha}) \\
G B R(k g / h a)\end{array}$ & $1.370,13$ & 253,42 & 577,79 & $1.046,50$ & $1.393,47$ & $1.365,15$ & $1.001,08$ \\
\hline $\begin{array}{l}\mathrm{RMSV}(\mathrm{kg} / \mathrm{ha}) \\
\text { GDMR }(\mathrm{kg} / \mathrm{ha})\end{array}$ & $2.774,29$ & $1.355,99$ & $1.507,84$ & $2.211,40$ & $2.330,15$ & $2.382,25$ & $2.093,65$ \\
\hline $\begin{array}{l}\mathrm{RT}(\mathrm{kg} / \mathrm{ha}) \\
T R(k g / h a)\end{array}$ & $4.869,65$ & $5.229,59$ & $4.582,86$ & $4.561,40$ & $3.759,47$ & $4.139,70$ & $4.523,78$ \\
\hline $\begin{array}{l}\mathrm{PB}(\%) \\
C P(\%)\end{array}$ & 6,12 & 5,16 & 5,75 & 6,13 & 7,00 & 6,06 & 6,04 \\
\hline $\begin{array}{l}\text { DIVMS }(\%) \\
\text { IVDMD (\%) }\end{array}$ & 52,67 & 50,28 & 48,00 & 49,05 & 55,27 & 52,65 & 51,32 \\
\hline
\end{tabular}


suplementados com AMI e A+O. Estas diferenças observadas foram de 48 e 30 dias para os níveis de suplementação 0,7 e $1,4 \%$ do peso vivo, respectivamente. Considerando o menor nível de suplementação (0,7\% PV), onde o período médio de suplementação para AMI foi de 205 dias, a utilização do suplemento $\mathrm{A}+\mathrm{O}$ reduziu a idade ao abate em $23,41 \%$ e o suplemento rico em óleo (OLE) reduziu em 3,9\%. Para o nível de $1,4 \%$ do PV, a redução de dias para o abate para os animais suplementados com $\mathrm{A}+\mathrm{O}$ quando comparado aos animais suplementados com AMI e OLE foi 30 e 21 dias ou 19,23\% ou 14,28\%, respectivamente. A diferença entre AMI e OLE foi de 5,77\% sendo necessário para o abate dos animais suplementados com AMI 9 dias a mais.

Quando se avaliaram individualmente os suplementos entre os dois níveis de fornecimento, observou-se que a suplementação de $1,4 \%$ do PV reduziu os dias para abate em 49, 50 e 31 dias para os animais suplementados com AMI, OLE e A+O, respectivamente. Considerando que a menor quantidade de dias para abate foi registrada para o lote suplementado com $\mathrm{A}+\mathrm{O}$ a $1,4 \%$ do $\mathrm{PV}$, e que o menor diferencial entre os dois níveis de suplementação foi para este suplemento, observou-se maior eficiência de utilização do concentrado $\mathrm{A}+\mathrm{O}$ fornecido a $0,7 \%$ do $\mathrm{PV}$, quando comparado aos demais suplementos nos diferentes níveis.

O desempenho produtivo é explicado por eventos biológicos e suas interações com o meio ambiente.

Tabela 7 - Dias para o abate (DPA) dos animais submetidos aos diferentes níveis e fontes de suplementos concentrados

Table 7 - Days to the slaughter (DTS) of animals in different levels and sources of concentrated supplement

\begin{tabular}{lcc}
\hline & \multicolumn{2}{c}{ DPA (dias) } \\
& \multicolumn{2}{c}{ DTS (days) } \\
\cline { 2 - 3 } Suplemento & $0,7 \% \mathrm{PV}$ & $1,4 \% \mathrm{PV}$ \\
Supplement & $.7 \% \mathrm{LW}$ & $1.4 \% \mathrm{LW}$ \\
\hline AMI & 205 & 156 \\
OLE & 197 & 147 \\
A+O & 157 & 126 \\
Média (Mean) & 186 & 143 \\
\hline
\end{tabular}

AMI: suplemento rico em amido, OLE: suplemento rico em óleo, A+O: suplemento de amido+óleo.

AMI: supplement rich in starch, OLE: supplement rich in oil, $A+O$ : supplement of starch +oil.

R. Bras. Zootec., v.32, n.6, p.1945-1955, 2003 (Supl. 2)
De outra forma, o resultado econômico depende da interação entre a resposta biológica e os parâmetros de mercado, isto é, valores de insumos e de venda do animal. Como estes parâmetros de mercado se apresentam em constante flutuação, grande parte dos autores opta em não inferir economicamente sobre os resultados de seus trabalhos. Por outro lado, o desenvolvimento científico direta ou indiretamente visa a aplicação prática. Esta, por sua vez, é utilizada de acordo com a resposta econômica gerada e seu impacto no faturamento e rentabilidade da empresa. Dessa forma, optou-se por avaliar economicamente os tratamentos do presente experimento, a fim do mesmo servir de balizamento para aplicação prática da tecnologia avaliada. Vale destacar que avaliação econômica foi pautada no diferencial gerado pela suplementação e não pelos valores absolutos obtidos.

Para avaliação dos parâmetros econômicos, além do ganho direto gerado pelo desempenho adicional dos animais, foram considerados os ganhos indiretos. A Tabela 8 apresenta os valores econômicos obtidos nos diferentes tratamentos e níveis de suplementação. A avaliação foi elaborada para 1 animal, aplicando-se a média dos resultados do suplemento fornecido e nível de suplementação em questão. Dentre os valores obtidos, o único afetado pela escala é o valor presente líquido (VPL), os demais permanecem inalterados.

Observou-se que em ambos os níveis de suplementação, o pior resultado foi para o suplemento rico em amido. O maior custo diário e menor ganho foram responsáveis pelo prejuízo gerado pelo referente tratamento.

O suplemento OLE apresentou o menor custo diário (Tabela 3), por outro lado, este fato não foi suficiente para gerar o maior resultado econômico. A TIR de 6,95 e 2,99\% obtida para os níveis 0,7 e 1,4\% do PV são suficientes para a suplementação com OLE ser colocada em prática. A suplementação com $\mathrm{A}+\mathrm{O}$, ao contrário do $\mathrm{AMI}$, apresentou, em ambos os níveis de suplementação, elevado resultado econômico. Isto se deve, principalmente, ao ganho médio diário (GMD) promovido por esta suplementação.

Outro importante dado econômico apresentado na avaliação é que os melhores resultados foram obtidos no menor nível de suplementação. Isto representa que os maiores ganhos médios diários promovidos quando o fornecimento de concentrado foi de $1,4 \%$ do PV teve eficiência econômica inferior à suplementação de $0,7 \%$ do PV. 
Tabela 8 - Investimento, valor presente líquido (VPL), taxa interna de retorno (TIR), relação benefício/custo (RBC) para um animal nos diferentes tratamentos

Table 8 - Investment, liquid present value (LPV), internal return rate (IRR), benefit cost ratio (BCR) to one animal in different treatments

\begin{tabular}{|c|c|c|c|c|c|}
\hline Suplemento & Nível (\% do PV) & Investimento $(\mathrm{R} \$)$ & $\begin{array}{l}\mathrm{VPL}(\mathrm{R} \$) \\
L P V(R \$)\end{array}$ & TIR (\%) & $\begin{array}{l}\mathrm{RBC} \\
B C R\end{array}$ \\
\hline Supplement & & & & & \\
\hline AMI & 0,7 & $\mathrm{R} \$ 138,35$ & $\mathrm{R} \$ 114,26$ & $-5,22 \%$ & $\mathrm{R} \$ 0,83$ \\
\hline OLE & 0,7 & $\mathrm{R} \$ 100,91$ & $\mathrm{R} \$ 121,48$ & $6,95 \%$ & $\mathrm{R} \$ 1,20$ \\
\hline $\mathrm{A}+\mathrm{O}$ & 0,7 & $\mathrm{R} \$ 96,16$ & $\mathrm{R} \$ 172,58$ & $24,99 \%$ & $\mathrm{R} \$ 1,79$ \\
\hline $\begin{array}{l}\text { Geral } \\
\text { Overall }\end{array}$ & 0,7 & $\mathrm{R} \$ 111,81$ & $\mathrm{R} \$ 115,03$ & $7,59 \%$ & $\mathrm{R} \$ 1,03$ \\
\hline AMI & 1,4 & $\mathrm{R} \$ 215,85$ & $\mathrm{R} \$ 147,96$ & $-12,57 \%$ & $\mathrm{R} \$ 0,69$ \\
\hline OLE & 1,4 & $\mathrm{R} \$ 155,26$ & $\mathrm{R} \$ 164,22$ & $2,99 \%$ & $\mathrm{R} \$ 1,06$ \\
\hline $\mathrm{A}+\mathrm{O}$ & 1,4 & $\mathrm{R} \$ 157,56$ & $\mathrm{R} \$ 198,60$ & $10,36 \%$ & $\mathrm{R} \$ 1,26$ \\
\hline $\begin{array}{l}\text { Geral } \\
\text { Overall }\end{array}$ & 1,4 & $\mathrm{R} \$ 176,22$ & $\mathrm{R} \$ 170,26$ & $-0,64 \%$ & $\mathrm{R} \$ 0,97$ \\
\hline
\end{tabular}

AMI: suplemento rico em amido, OLE: suplemento rico em óleo, A+O: suplemento de amido+óleo.

AMI: supplement rich in starch, OLE: supplement rich in oil, $A+O$ : supplement of starch + oil.

\section{Conclusões}

A suplementação com concentrados compostos pela mistura de alimentos ricos em amido (milho) e óleo (caroço de algodão) proporcionou melhor desempenho dos animais, do que quando suplementados separadamente com as respectivas fontes, independentemente do nível de suplementação. O maior nível de suplementação (1,4\% do PV) apresentou eficiência econômica inferior, quando comparado ao menor nível ( $0,7 \%$ do PV).

\section{Literatura Citada}

ALBERTO, E. Effectos de la calidade de los forrajes y la suplementacion en el desempeño de ruminantes em pastoreo (com especial referencia a vacas lecheras). In: SIMPÓSIO SOBRE AVALIAÇÃO DE PASTAGENS COM ANIMAIS, 1997, Maringá. Anais... Maringá: Universidade Estadual de Maringá, 1997. p.53-73.

CATON, J.S.; DHUYVETTER, D.V. Influence of energy supplementation on grazing ruminants: requirements and responses. Journal of Animal Science, v.75, n.2, p.533$542,1997$.

COELHODA SILVA, J.F.; LEÃO, M.I. Fundamentos de nutrição de ruminantes. Piracicaba: Livroceres. 1979. 380p.

DOSSA, D.; GUIMARÃES, F.; CANZIANI, J.R. Manual técnico de administração rural - Manual do instrutor. Curitiba: Senar PR, 1991. 241p.

EUCLIDES, V.P.B.; EUCLIDES FILHO, K.; ARRUDA, Z.J. et al. 1997. "Alternativas de suplementação para a redução de idade de abate de bovinos em brachiária decumbens", http:/ /www.cnpgc.embrapa.br/publicacoes/ct (15/06/2000).

GALYEAN, M.L.; OWENS, F.N. Effects of diet composition and level of feed intake on site and extent of digestion in ruminants. In: TSUDA, T.; SASAKE, Y.; KAWASHIMA, R. (Eds.) Physiological aspects of digestion and metabolism in ruminants. San Diego: Academic Press, 1991. p.483-505.

GRANT, J.J. Influence of corn and sorghum starch on the in vitro kinetics of forage fiber digestion. Journal of Dairy Science, v.77, n.6, p.1563-1569, 1994.

HARMON, D.L. Nutritional regulation of postruminal digestive enzymes in ruminants. Journal of Dairy Science, v.76, n.7, p.2102-2111, 1993.

HOLDEN, L.A. Comparison of methods of in vitro dry matter digestibility for ten feeds. Journal of Dairy Science, v.82 n. 8, p.1791-1794, 1999.

HUCK, G.L.; KREIKEMEIER, G.L.; KUHL, T.P. et al. Effect of feed combinations of steam flaked, high-moisture, or dry rolled corn on growth performance and carcass characteristics in feedlot cattle. Journal of Animal Science, v.76, n.12, p.2984-2990, 1998.

HUNTINGTON, G.B. Starch utilization by ruminants: from basics to the bunk. Journal of Animal Science, v.75, n.3, p.852-867, 1997.

KREIKEMEIER, K.K.; HARMON, D.L.; BRANDT Jr., R.T. Effect of various levels of abomasal glucose, corn starch and corn dextrin on small intestinal disappearance and net glucose absorption. Journal of Animal Science, v.69, n.1, p.328338, 1991.

MACZULAC, A.E.; DEHOROTY, B.A.; PALMQUIST, D.L. Effects of long chain fatty acids on growth of rumen bacteria. Applied Environmental Microbiology, v.42, n.5, p.856862, 1981.

MAGAlHÃES, C.A. Planejamento da Empresa rural Métodos de planejamento e processo de avaliação. Viçosa, MG: Universidade Federal de Viçosa, 1995. 99p.

MARASCHIN, G.E. Sistemas de pastejo. In: PEIXOTO, A.M.; MOURA, J.L.; FARIA, V.P. (Ed.) Pastagens: Fundamentos da exploração racional. 2.ed. Piracicaba: Fundação de Estudos Agrários Luiz de Queiroz, 1994. p.337-376.

R. Bras. Zootec., v.32, n.6, p.1945-1955, 2003 (Supl. 2) 
MEHREZ, A.S.; ORSKOV, E.R. A study of artificial fiber bag tecnique for determining the digestibility of feeds in the rumen. Journal of Agricultural Science, v.88, p.645-650, 1977.

MOORE, J.E.; BRANT. M.H.; KUNKLE, W.E. et al. Effects of supplementation on voluntary forage intake, diet digestibility and animal performance. Journal of Animal Science, v.7, (suppl2/J), p.22-135, 1999.

MOTT, G.O.; LUCAS, H.L. The design, conduct and interpretation of grazing trials on cultivated and improved pastures. In: INTERNACIONAL GRASSLAND CONGRESS, 1952, Pensylvania. Proceedings... Pensylvania: State College Press, 1952. p.1380-1385.

NATIONAL RESEARCH COUNCIL - NRC. Nutrient requirements of beef cattle. 7.ed. Washington, D.C.: National Academy Press, 1996. 242p.

OWENS, F.N.; ZINN, R.A.; KIM, Y.K. Limits to starch digestion in the ruminant small intestine. Journal of Animal Science, v.63, p.1634, 1986.

PEDREIRA, J.R.A.; ROSSI, P. Manual prático de avaliação nutricional de alimentos. Piracicaba: Fundação de Estudos Agrários Luiz de Queiroz, 1995. 95p.

PORDOMINGO, A.J.; WALLACE, J.D.; FREEMAN, A.S. et al. Supplemental corn grain for steers grazing native rangeland during summer. Journal of Animal Science, v.69, n.4, p.1678-1687, 1991.

POORE, M.H.; ECK, T.P.; SWINGLER, R.S. et al. Total starche and relative starch of feed grains. In: BIENNIAL CONFERENCE ON RUMEN FUNCTION, 20., 1989, Chicago. Proceedings... Chicago: 1989. 10p.

RIBEIRO, H.M.N.; MENDES, G.; FROHMUT, K. et al. Efeito de concentrado sobre consumo de volumoso e energia metabolizável (EM) em novilhos. In: REUNIÃO ANUAL DA SOCIEDADE BRASILEIRA DE ZOOTECNIA, 36., 1999, Porto Alegre. Anais... São Paulo:Sociedade Brasileira de Zootecnia/Gmosis, [1999] 17 par. CD-ROM. NUR. Consumo e valor nutritivo. 106.

RUSSEL, J.B. Estrategies that ruminal bacteria use to handle excess carbohydrate. Journal of Animal Science, v.76, n.7, p.1955-1963, 1998.

SANTOS, J.E; ALMSTANDEN, M. Lipids and rumen digestion. In: Arquivos da Faculdade de Veterinária UFRGS, v. 26 p.19-89, 1991.
SILVA, D.J. Análise de alimentos: métodos químicos e biológicos. Viçosa, MG: Universidade Federal de Viçosa, 1990. 165p.

TILLEY, J.M.A.; TERRY, R.A. A two-stage technique for the in vitro digestion of forrage crops. Journal of Britain Grassland Society, v.18 p.104-111, 1963.

THIAGO, L.R.L.S. "Suplementação de Bovinos em pastejo (aspectos práticos para seu uso na mantença e ganho de peso)", 1999. http://www.cnpgc.embrapa.br/publicacoes/ naoseriadas $(15 / 06 / 2000)$.

UNIVERSIDADE FEDERAL DE VIÇOSA - UFV. SAEG (Sistemas de Análises Estatísticas e Genéticas). Viçosa, MG (Versão 7.0), 1997.

VALADARES FILHO, S.C. Nutrição, avaliação de alimentos e tabelas de composição de alimentos para bovinos In: REUNIÃO ANUAL DA SOCIEDADE BRASILEIRA DE ZOOTECNICA, 37., 2000, Viçosa, MG. Anais... Viçosa, MG: Sociedade Brasileira de Zootecnia, 2000. p.267-339.

VAN SOEST, P.J. Nutritional ecology of the ruminant. 2.ed. Cornell: University Press, 1994. 476p.

VILLELA, S.D.J.; VALADARES FILHO, S.C.; SILVA, J.F.C. et al. Caroço de algodão para vacas leiteiras 2. Efeito na digestão parcial dos nutrientes, taxa de passagem da digestão ruminal e degradação da matéria seca e proteína bruta, Revista Brasileira de Zootecnia, v.26, n.1, p.196-194, 1997.

WILM, HG.; COSTEllo, O.F.; KLIMPPLE, G.E. Estimating forage yield by the double sampling method. Journal of American Society of Agronomy, v.36, n.1, p.194-203, 1944.

ZEOULA, L.M.; CALDAS NETO, S.F. Recentes avanços em amido na nutrição de vacas leiteiras. In: SIMPÓSIO INTERNACIONAL EM BOVINOCULTURA DE LEITE, 2., 2001, Lavras. Anais... Lavras: Universidade Federal de Lavras/ Triple-S [2001]. CD-ROM. Palestras.

ZINN, R.A.; PLASCENCIA, A. Interaction of whole cottonseed and supplemental fat on digestive function in cattle. Journal of Animal Science, v.71, n.1, p.11-17, 1997.

Recebido em: 27/08/02 Aceito em: 14/04/03 